\title{
BACILLARY DYSENTERY
}

\author{
BY

\section{NELLES SILVERTHORNE, M.B. AND AGNES WALKER}

(From the Wards and Laboratories of the Hospital for Sick Children and the Department of Paediatrics, University of Toronto, under the direction of Alan Brown, M.D., F.R.C.P., and from the Connaught Laboratories, University of Toronto)

The following communication is a survey of a group of patients with dysentery admitted to the Hospital for Sick Children, Toronto, from May 1939 to May 1941 inclusive. In all cases stool cultures were obtained showing a known pathogen. The report deals with clinical and bacteriological aspects of the disease. Brown et al. (1930) and Johnston et al. $(1930,1933)$ published a series of reports on the isolation of dysenteric micro-organisms from the stools of patients with 'intestinal intoxication.'

Clinical data. The present report deals with the investigation of twentynine infants and children with bacteriologically-proven dysentery. The ages of the group varied from two months to nine years of age. The main symptoms in order of frequency were as follows: fever (28), diarrhoea (22), vomiting (13), blood in stools (7), drowsiness (7), convulsions (5), and abdominal pain (5). None of the infants was receiving breast milk at the time of its illness. Twenty-eight of the twenty-nine patients lived in the city. Twenty-two of the patients were admitted during the months of August, September, October and November. Three patients were admitted in the month of May, three in December and one in March. There were sixteen males and thirteen females in the group. Twenty-three of the group had fever which varied between $100^{\circ}$ and $104^{\circ} \mathrm{F}$. In twenty-two of the twenty-nine patients the temperature fell by crisis in twenty-four to forty-eight hours after admission. The patients were treated in the main with fluids by mouth and a mixture containing bismuth salicylate and camphorated tincture of opium with chalk. Those patients who were more seriously ill received a continuous intravenous injection of glucosesaline and in some instances a blood transfusion. One patient received sulphathiazole and one patient received sulphaguanidine by mouth. All patients showed marked clinical improvement in the course of twenty-four to fortyeight hours.

Bacteriological data. The twenty-nine strains of dysentery cultures obtained from the stools of the patients were examined for morphology, for their reactions in various carbohydrate media and for their agglutination in specific rabbit sera. Twenty-three strains were found to be B. dysenteriae Sonne. 
The remaining six strains were as follows: B. dysenteriae Flexner W (3), Flexner Y (1), Newcastle (2).

\section{Discussion}

Eighteen of the twenty-nine patients were two years of age and older and from a clinical standpoint it is possible that the disease was less severe than previously reported by Johnston et al. (1930) in younger age groups. In none of the groups did a death occur, in spite of the fact that only two patients received the sulphonamide group of drugs. In a discussion of the results of treatment in a group of patients with dysentery at the present time, it is important to mention the form of treatment employed. At present sulphaguanidine is being used in the treatment of dysentery with good results. This group of patients was treated with enteral and parenteral fluids, and it would be difficult to see from the results how they could be improved upon by the use of sulphaguanidine. Had this chemotherapeutic agent been used it would have been tempting to conclude that the drug was partially responsible for the rapid clinical recovery. The carrier state was not observed to be present in any case in this series. The investigation of the causes of dysentery in this group reveals that $\mathbf{B}$. dysenteriae Sonne was by far the commonest offending micro-organism.

\section{Summary}

1. Clinical and bacteriological data are reported on twenty-nine patients with dysentery.

2. All patients recovered rapidly as a result of the administration of fluids.

3. Twenty-three of the twenty-nine patients were suffering from dysentery as a result of B. dysenteriae Sonne, three as a result of B. dysenteriae Flexner W, one as a result of $B$. Flexner $Y$ and two as a result of B. Newcastle.

\section{REFERENCES}

Brown, Alan, et al. (1930). Sth. med. J., 23, 107.

Johnston, M. M., et al. (1930). Canad. med. Ass. J., 23, 231. and Brown, A. (1930). Canad. publ. Hlth. J., 21, 395

_ et al. (1933). Amer. J. Dis. Child., 45, 1. 